\title{
Soil liquefaction as an identification test
}

\author{
Bozana Bacic $^{1, *}$ and Ivo Herle ${ }^{1}$ \\ ${ }^{1}$ Technische Universität Dresden, Institute of Geotechnical Engineering
}

\begin{abstract}
Time-consuming and complicated investigations of soil liquefaction in cyclic triaxial tests are the most common way of laboratory analysis of this phenomenon. Moreover, the necessary equipment for the performance of cyclic triaxial tests is very expensive. Much simpler method for laboratory testing of the soil liquefaction has been developed at the Institute of Geotechnical Engineering at the TU Dresden. This method takes into account the pore water pressure build-up during cyclic shearing within a short time period. During the test, the soil sample is subjected to horizontal cyclic loading and the generated pore water pressure is measured. In the first series of these experiments, a dependence of the pore water pressure buildup on the initial density of soil could be observed, as expected. When comparing different soils, it is shown that the tendency to liquefaction depends also on the granulometric properties (e.g. grain size distribution) of the soil. The aim of the further development is to establish a simple identification test for laboratory testing of the soil liquefaction.
\end{abstract}

\section{Introduction}

Soil is usually a multi-phase material, consisting of three main components. These are solid soil grains, air and water which fill the pore space between the soil grains. It is well agreed that the amount of water in soil has a significant effect on the undrained soil behaviour [1-5]. In the dry condition $\left(S_{r}=0 \%\right)$, the mechanical response of the soil depends only on the behaviour of soil skeleton, as the pore space is filled by air whose density and stiffness can be ignored when compared with the soil skeleton. On the other hand, when the pore space is occupied by water (full saturation, $S_{r}=100 \%$ ) or air-water mixture (partial saturation, $S_{r}<100 \%$ ), the mechanical response of the soil depends not only on the soil skeleton but also on the fluid in the pore space.

In this study, the degree of saturation of 14 different sands was initially tested in the laboratory. Loose sand specimens were slowly saturated from the bottom to the top and the degree of saturation was determined from the mass of water in the specimen. The results show that values of the obtained degree of saturation strongly depend on the granulometric properties of tested sands. Additionally, the accumulation of PWP for two different sands was determined using the newly developed identification test. In this test the evolution of excess pore water pressure in a water-saturated specimen under horizontal cyclic shearing is measured. By testing different sands, an information about the tendency to liquefaction for each of the tested sands is obtained. As this tendency is different for different sands it can be considered as an index property of the particular sand (in analogy to e.g. the minimum and maximum densities of the soil).

*e-mail: bozana.bacic@tu-dresden.de

\section{Laboratory testing of the soil saturation}

\subsection{Tested materials}

For purposes of this study 14 different medium- and coarse-grained sands were used. The grain size distribution curves of the tested sands can be taken from Figure 1. Index properties of these sands are given in Table 1.

Table 1. Index properties of the tested sands $\left(C_{u} \ldots\right.$ coefficient of uniformity)

\begin{tabular}{cccccc}
\hline Sand & $\varphi\left[^{\circ}\right]$ & $e_{\min }[-]$ & $e_{\max }[-]$ & $C_{u}[-]$ & $d_{50}[\mathrm{~mm}]$ \\
\hline 1 & 30.00 & 0.579 & 0.865 & 1.20 & 0.943 \\
2 & 34.13 & 0.622 & 0.918 & 1.50 & 1.266 \\
3 & 30.00 & 0.493 & 0.838 & 2.41 & 0.517 \\
4 & 35.04 & 0.620 & 1.058 & 3.45 & 0.793 \\
5 & 32.68 & 0.417 & 0.713 & 2.30 & 0.507 \\
6 & 33.51 & 0.472 & 0.825 & 2.36 & 0.358 \\
7 & 35.11 & 0.412 & 0.921 & 1.50 & 1.266 \\
W1 & 32.05 & 0.556 & 0.892 & 1.89 & 0.436 \\
W3 & 34.13 & 0.546 & 0.846 & 2.20 & 0.621 \\
W4 & 32.68 & 0.372 & 0.849 & 2.73 & 0.753 \\
W5 & 35.11 & 0.404 & 0.899 & 2.91 & 0.589 \\
W7 & 34.13 & 0.395 & 0.906 & 2.83 & 0.626 \\
W8 & 32.68 & 0.449 & 1.023 & 3.01 & 0.646 \\
W9 & 35.11 & 0.561 & 0.901 & 1.86 & 0.417 \\
\hline
\end{tabular}

\subsection{Testing procedure}

The dry funnel pluviation method followed by a slow saturation of the installed specimens from the bottom to the top 


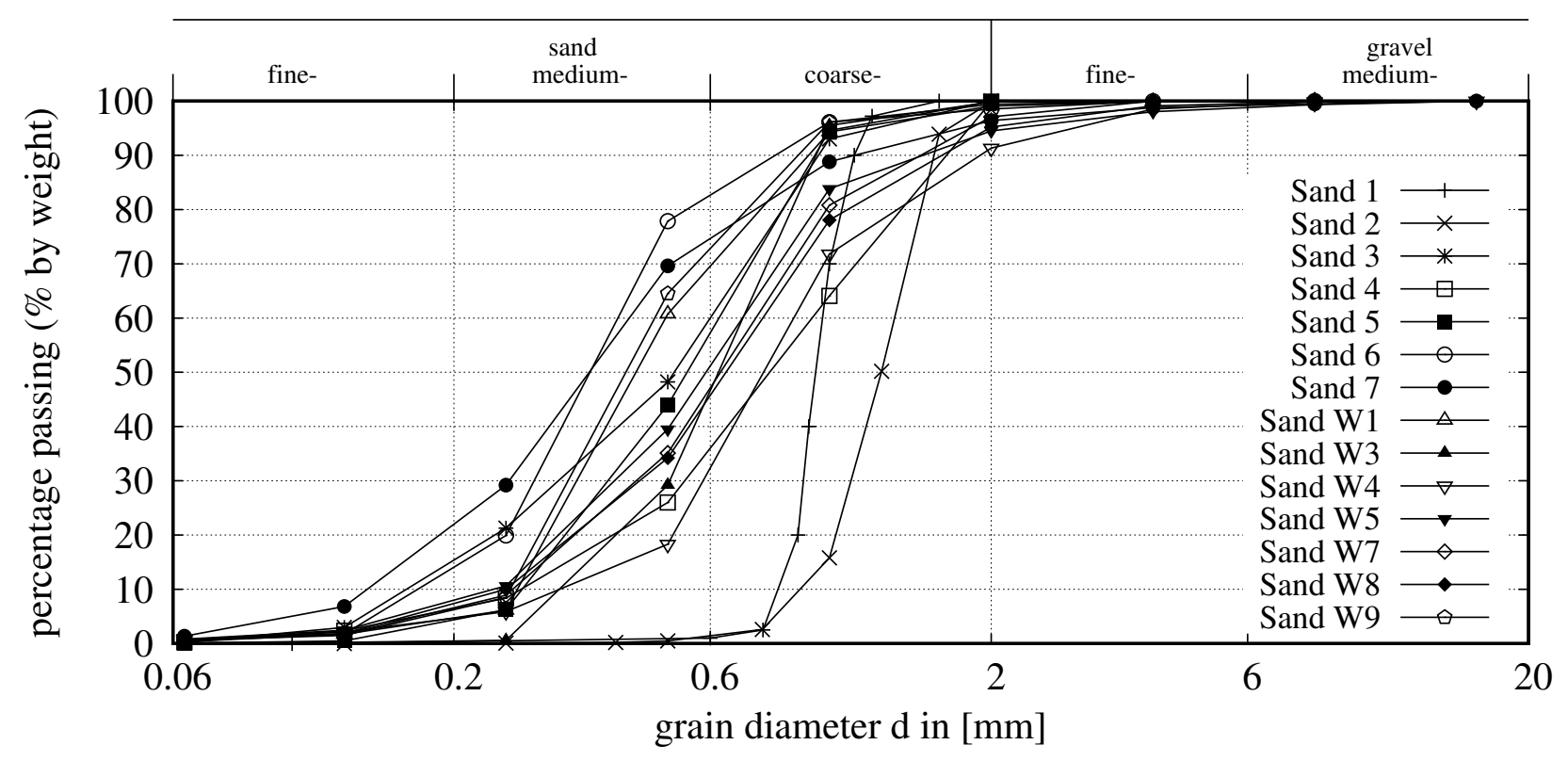

Fig. 1. Grain size distribution curves of the tested sands

was used to investigate the influence of the soil granulometry on the degree of saturation. Two test series were conducted: with and without a rubber membrane surrounding the soil specimen.

For installation and saturation of the sand specimens, a steel cylinder with dimensions $D / H=70 / 112 \mathrm{~mm}$ (1) and a permeable bottom (2) was used (Figure 2).

The steel cylinder was placed on a scale (3) to measure the mass of the water inside of the specimen after saturation. Specimens were installed in dry condition using a glass funnel (4), thus very loose sand packings $\left(D_{r 0} \approx 0.1\right)$ were obtained. Saturation of the specimens was achieved by a difference in the total water head of the water tank and the steel cylinder $-h_{w, \operatorname{tank}, 0}>h_{w, c y l, 0}(5)$. After each test, the amount of water in a particular specimen was added to the water tank to ensure a constant water head difference in all tests. The height of water in the cylinder prior to saturation was at the bottom of the cylinder, $h_{w, c y l, 0}$. After saturation of the sand specimen, the final settlements of the sand upper surface were measured at three positions and the average value $\left(s_{\text {avg }}\right)$ was built.

The height of the specimen $(h)$ was determined as a difference between the height of the cylinder $(H)$ and the average settlement $\left(s_{\text {avg }}\right)$. The diameter of the specimen was equal to the inner diameter of the cylinder $(d=D)$. Using Equation 1 and the determined mass of the water in the specimen, the degree of saturation of each specimen was calculated.

$$
S_{r}=\frac{w \cdot \rho_{s} \cdot \rho_{d}}{\rho_{w} \cdot\left(\rho_{s}-\rho_{d}\right)} \cdot 100[\%]
$$

Here, $w$ is water content, $\rho_{d}$ is the density of the specimen, $\rho_{s}$ is the grain density and $\rho_{w}$ is the water density.

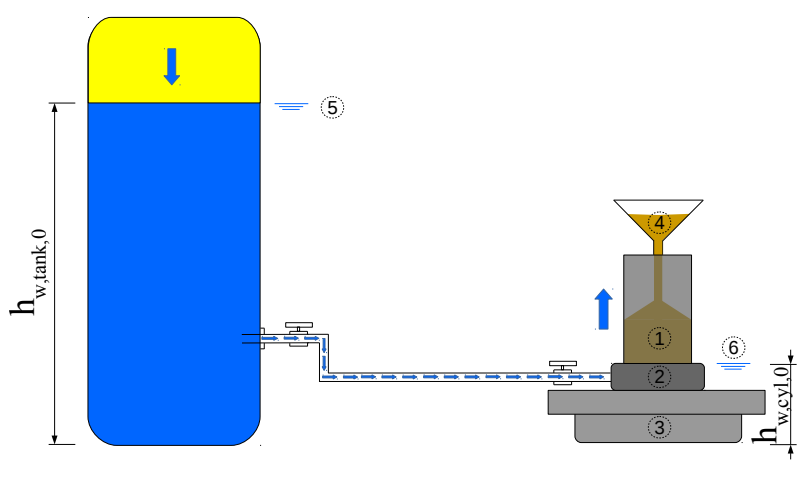

Fig. 2. Experimental setup for testing of sand saturation

\subsection{Obtained results}

The results of the above described laboratory tests show that a full saturation cannot be achieved by simply flooding the sample. In case of the identical saturation procedure, the degree of saturation of the tested sands reaches between 75 and $98 \%$.

These results are summerized in Figure 3 where a dependence of $S_{r}$ on $C_{u}$ is shown. It is obvious that the degree of saturation decreases as the uniformity coefficient increases. The results indicate that uniformly graded sands can be better saturated than well graded sands. This trend is observed in both tests, with and without membrane. The average value of $S_{r}$ in both test series is close to $88 \%$ with the standard deviation of $5 \%$. To check the scatter of the results, the test was repeated on each sand three times. The maximum scatter of $S_{r}=4 \%$ was observed (in case of Sand 7).

A dependence of the average settlements on the uniformity coefficient of the tested sands is presented in Figure 


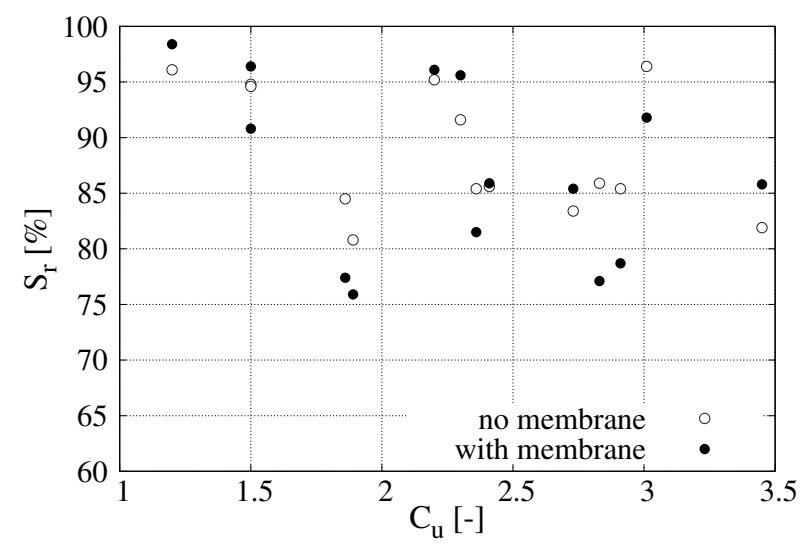

Fig. 3. Dependency of $S_{r}$ on $C_{u}$ for the tested sands

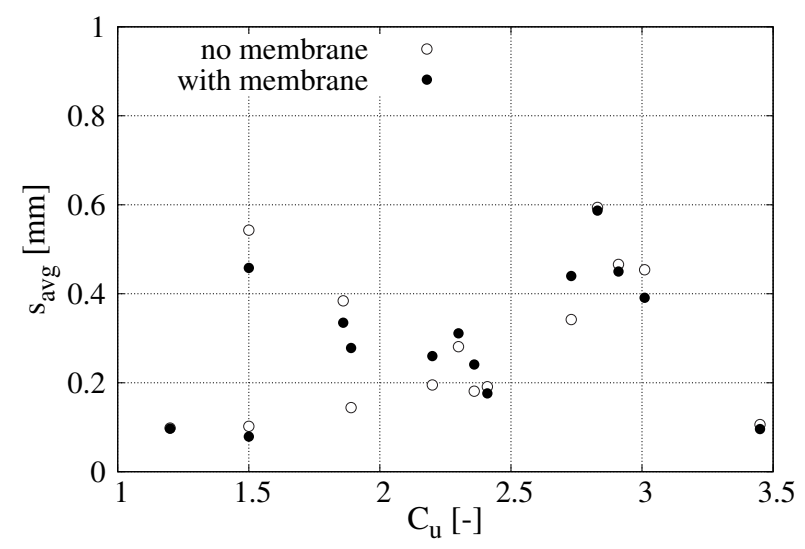

Fig. 4. Dependency of $s_{\text {avg }}$ on $C_{u}$ for the tested sands

4. The results show that well graded sands settle more than uniformly graded sands, as during the slow saturation of the specimen the fine grains can rearrange into the pore spaces between the coarse grains. This tendency was observed in both test series. The maximum scatter of the measured settlements $(0.1 \mathrm{~mm})$ was observed in case of Sand W4.

\section{Identification test}

The newly proposed test is based on registering the evolution of excess PWP due to cyclic shearing of a watersaturated sand specimen. It enables a fast installation of the specimen and provides results in a short time. In this test a water-saturated soil specimen is cyclically loaded in horizontal direction, which causes a simple shear deformation in undrained conditions. This undrained shearing results in build-up of excess PWP. By measuring the evolution of excess PWP in certain number of cycles, the tendency to liquefaction of different sands can be estimated.

As shown above, the initial degree of saturation of the tested sands lies in a wide band of approximately $23 \%$. An excess pore-water pressure (PWP) due to shear (tendency to liquefaction) in a loose sand is strongly influenced by the degree of saturation. Thus, it can be expected that for the outlined saturation procedure the results of the liquefaction tests will be sensitive to the initial value of $S_{r}$.

\subsection{Test performance}

A sketch of the experimental set-up of the identification test is presented in Figure 5. At the beginning of the test, a loose sand specimen (1) of dimensions $D / H=$ $50 / 100 \mathrm{~mm}$ is installed. After specimen installation, effective stress is equal to zero. The external loading (total stress, $p$ ) corresponds to the relative air pressure (2). The total stress remains unchanged and equal to zero during the entire test. To increase the initial effective stress in the specimen, a suction (negative PWP) is applied to the bottom of the specimen (3). Considering that the total stress is equal to zero, the effective stress $\left(p^{\prime}\right)$ is increased to the value of the negative PWP $(u)$. The value of the initial effective stress follows from Equation 2.

$$
p=p^{\prime}+u=0 \rightarrow p^{\prime}=p-u>0 k P a
$$

Herein, the stresses are considered positive in case of compression.

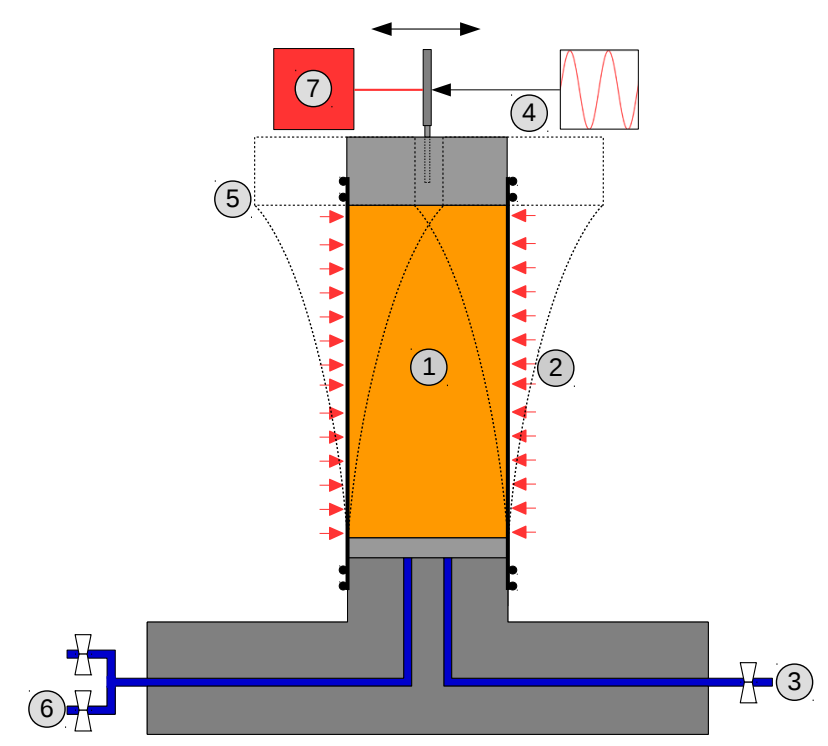

Fig. 5. Experimental set-up of the identification test

Subsequently, the specimen is cyclically loaded in undrained conditions (4) keeping the suction valve (3) closed. The loading is performed by rigidly translating the top plate of the specimen in the horizontal direction. In this way, the specimen swings in direction of loading (5) and a mode of simple shearing is achieved. The cyclic loading occurs under controlled displacement amplitude and frequency. During the test, the air pressure and the excess PWP are measured and evaluated. The measurement of the excess PWP occurs at the bottom of the specimen (6). The displacement of the top plate is measured using a laser contactless distance sensor (7). The duration of one complete test is approximately 30 minutes including the specimen installation. 


\subsection{Test results}

In this paper, liquefaction tests on Sands W7 and W1 are discussed. Initial effective stress was $p_{0}^{\prime}=30 \mathrm{kPa}$ and the loading was terminated after the effective stress decreased to $p^{\prime}=10 \mathrm{kPa}$, in order to compare the number of loading cycles necessary for the same decrease of effective stress in case of different soils. The loading amplitude and frequency were set to $A=4.5 \mathrm{~mm}$ and $f=1 \mathrm{~Hz}$, respectively. Specimens were installed in 8 layers using the undercompaction method proposed by Ladd [6] and subsequently saturated from the bottom to the top. The degree of undercompaction was $U=10 \%$ with the water content $w=5 \%$.

Results of the liquefaction tests are summerized in Table 2 and in Figure 6.

Table 2. Initial states and number of loading cycles for $\Delta p^{\prime}=20 \mathrm{kPa}(N)$ in tests on Sands W7 and W1 $\left(D_{r 0} \ldots\right.$ initial relative density)

\begin{tabular}{ccccc}
\hline Nr. & Sand & $D_{r 0}[-]$ & $S_{r}[\%]$ & $N[-]$ \\
\hline 1 & W7_1 & 0.502 & 71 & 57 \\
2 & W7_2 & 0.375 & 59 & 92 \\
3 & W7_3 & 0.377 & 60 & 105 \\
4 & W1_1 & 0.306 & 68 & 307 \\
5 & W1_2 & 0.373 & 73 & 335 \\
6 & W1_3 & 0.414 & 75 & 474 \\
\hline
\end{tabular}

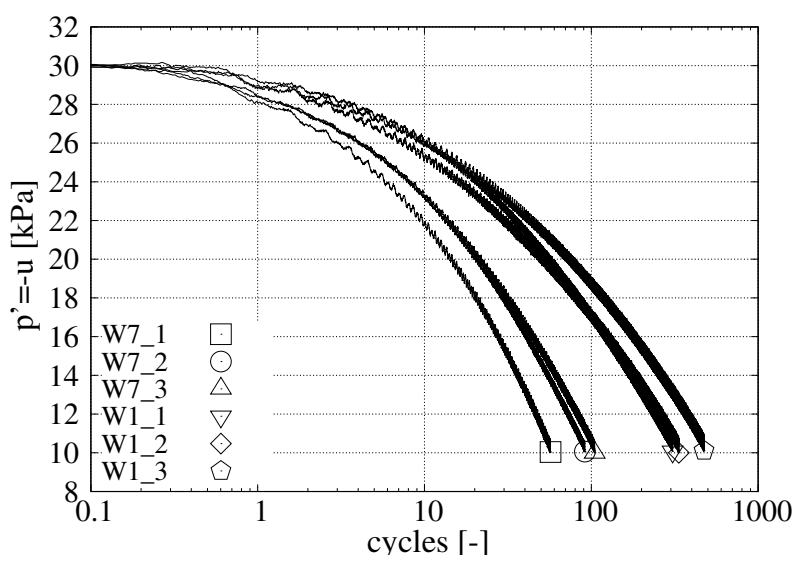

Fig. 6. Results of the liquefaction tests on Sands W7 and W1

Low values of $S_{r}$ in these tests coincide with the observations in the saturation tests on these two sands. Liquefaction tests prove the reproducibility of the test results, since a similar number of cycles was obtained when loading the specimens with similar initial states (W7_1 and W7_2, as well as W1_1 and W1_2). It can be also observed, that the tendency to liquefaction of Sand W7 is higher than of Sand W1, since for similar $D_{r 0}$ and $S_{r}$ Sand W1 sustains a higher number of cycles. Obviously, sands with different granulometry but similar initial states have different ability to liquefy. This tendency to acumulate the PWP under defined initial and loading conditions is different for different soils and indicates which soil is more susceptible to soil liquefaction.

\section{Conclusion and outlook}

The investigation of the saturation of 14 different sands has demonstarted that a full specimen saturation cannot be achieved by slowly saturating the specimen from the bottom to the top.

The results indicate that the degree of saturation decreases as the uniformity coefficient increases. Additionaly, well graded sands settle more than uniformly graded sands during the saturation.

The liquefaction tests on Sands W7 and W1 confirm the reproducibility of the newly proposed methodology. They also show that accumulation of the PWP depends on granulometry.

The presented approach to liquefaction laboratory testing enables a fast investigation of the liquefaction potential under different conditions. An alternative approach is needed to reach in a fast and simple way a high degree of saturation. Subsequently, various factors influencing the soil liquefaction can be tested in a routine way.

In the next phase, a dimensionless liquefaction index will be introduced. This index should represent the evolution of the PWP in certain number of cycles for defined initial and loading conditions. By comparing the liquefaction index for different soils, it should be possible to predict which soil liquefies faster under the same initial and loading conditions.

The authors would like to thank Prof. Torsten Wichtmann for providing several sands for this study. DFG (German Research Foundation) financially supported this research (grant Nr. HE 2933710-1).

\section{References}

[1] N. Della, A. Arab, Acta Polytechnica Hungarica 7, 143 (2010)

[2] A. Arab, M. Belkhatir, M. Sadek, Geotechnical and Geological Engineering 34, 347 (2015)

[3] M. Okamura, Y. Soga, Soils and Foundations 46, 695 (2006)

[4] M.A. Sherif, C. Tsuchiya, I. Ishibashi, Journal of the Geotechnical Engineering Division 103, 914 (1977)

[5] C.A. Vega-Posada, R.J. Finno, D.G. Zapata-Medina, Journal of Geotechnical and Geoenvironmental Engineering 140 (2014)

[6] R. Ladd, Geotechnical Testing Journal 1, 16 (1978) 